\title{
Selective degradation of cyclin B1 mRNA in rat oocytes by RNA interference (RNAi)
}

\author{
Shlomi Lazar, Eran Gershon and Nava Dekel \\ Department of Biological Regulation, Weizmann Institute of Science, Rehovot 76100, Israel \\ (Requests for offprints should be addressed to N Dekel; Email: nava.dekel@weizmann.ac.il)
}

\begin{abstract}
Cyclic adenosine monophosphate (CAMP) keeps oocytes in meiotic arrest, thereby preventing activation of the key regulators of meiosis, p34cdc2/cyclin B1, (known as maturation-promoting factor (MPF)) and Erk 1 and 2, members of the mitogen-activated protein kinase (MAPK) family. The activity of MAPK in oocytes is upregulated by Mos. We previously demonstrated that Mos translation in rat oocytes is negatively regulated by a PKA-mediated cAMP action, which inhibits c-mos mRNA polyadenylation and is associated with the suppression of p34 cdc2 kinase. The goal of the present study was to provide definitive evidence that Mos translation is subjected to MPF regulation. In order to inhibit MPF activity, we employed the double-stranded (ds) RNA interference (RNAi) of gene expression. We demonstrated that the introduction of cyclin B1 dsRNA into rat oocytes selectively depleted the corresponding mRNA, further ablating its protein product. These oocytes, which exhibit low MPF activity, failed to elongate the c-mos mRNA poly $(A)$ tail, did not accumulate Mos and were unable to activate MAPK. We conclude that an active MPF in rat oocytes is necessary for c-mos mRNA polyadenylation and Mos translation.
\end{abstract}

Journal of Molecular Endocrinology (2004) 33, 73-85

\section{Introduction}

Meiosis in oocytes of all animals is arrested at the prophase that corresponds to the late G2-phase of the cell-division cycle. The G2-arrested oocytes are characterized by a distinct nuclear structure known as germinal vesicle $(\mathrm{GV})$. Oocytes that escape G2-arrest undergo GV breakdown (GVB) and chromosome condensation. These oocytes proceed to the first metaphase (MI), emit the first polar body $(\mathrm{PBI})$ and are arrested again at the second metaphase (MII) of meiosis. This process, defined as oocyte maturation, is subjected to regulation by the maturation-promoting factor (MPF), which comprises a catalytic $34 \mathrm{kDa}$ Ser/Thr kinase, p34 cdc2, and a regulatory $45 \mathrm{kDa}$ cyclin Bl (reviewed by Dekel 1996). Members of the MAP kinase (MAPK) family, the 42 and $44 \mathrm{kDa}$ Erk 1 and 2, also participate in the regulation of meiosis (for reviews, see Gotoh et al. 1995, Dekel 1996). The signal for MAPK activation is mediated by a MAPK kinase (MEK), which, in oocytes, is activated by Mos (for review, see Sagata 1997).
Activation of both p34 cdc2 and MAPK accompanies the reinitiation of meiosis. On the other hand, a cAMP-activated protein kinase A (PKA) maintains the oocytes in meiotic arrest (Maller \& Krebs 1977, Dekel \& Beers 1978, Bornslaeger et al. 1986). The negative effect of cAMP on the resumption of meiosis is associated with an inhibited activation of both MPF (Choi et al. 1991, Goren \& Dekel 1994) and MAPK (Lazar et al. 2002), suggesting that these two enzymes act downstream to PKA. Their sequential order, however, is still a matter of intensive debate.

Simultaneous activation of both enzymes in Xenopus oocytes (Gotoh et al. 1991a,b, Nebrada \& Hunt 1993) cannot disclose their sequence and, consequently, attempts to study their interrelationships in this animal model generated controversial results. A number of earlier studies suggested that a Mos-activated MAPK is necessary for MPF activation (Yew et al. 1992, Kosako et al. 1994), and the G2 to M transition (Freeman et al. 1989, Sagata et al. 1989, Gotoh et al. 1995, Haccard et al. 1995, Huang et al. 1995, Sheets et al. 1995, Gross et al. 2001). Later reports, however, denied a role for the 
Mos/MAPK pathway at the reinitiation of meiosis (Fisher et al. 1999, Gross et al. 2000, Dupre et al. 2002). On the other hand, other studies demonstrated that MAPK activation is dependent on an active MPF (Ferrell et al. 1991, Gotoh et al. 1991a, Nebrada et al. 1995, Culp \& Musci TJ 1999, Frank-Vaillant et al. 1999).

A similar confusion regarding the interplay between MPF and MAPK has been presented by results generated by using murine oocytes (Zhao et al. 1990, O'Keefe et al. 1991, Verlhac et al. 1994). This confusion in the mouse has been partially resolved by demonstrations showing that the ability of oocytes derived from Mos knockout mice to activate MPF is not impaired (Araki et al. 1996, Choi et al. 1996, Verlhac et al. 1996). Elevation of MPF activity in rodent oocytes resuming meiosis occurs prior to MAPK activation (Gavin et al. 1994, Verlhac et al. 1994, Zernicka-Goetz et al. 1997). This further supports the idea that MPF is not subject to regulation by MAPK. Nevertheless, a reverse hierarchy between these two kinases is possible.

A recent study in our laboratory demonstrated that translation of Mos in rat oocytes is negatively regulated by a PKA-mediated cAMP action. This action that inhibits c-mos mRNA polyadenylation is associated with the suppressed activity of p34 cdc2 (Lazar et al. 2002). Interference with p34 cdc2 activity in that study was achieved by exposing the oocytes to roscovitine, a purine analog that potently inhibits the activity of this kinase (Meijer \& Kim 1997). Roscovitine, the affinity of which to p34 cdc2, is relatively high, elicits its inhibitory action by competing with ATP binding in a variety of protein kinases (Meijer et al. 1997). Therefore, conclusive evidence for the role of MPF in regulating Mos expression required the use of a specific molecular strategy. This requirement has been fulfilled by disturbing p34 cdc2 activity through the double-stranded (ds) RNA interference (RNAi), which was targeted at the expression of cyclin Bl mRNA. Employing this technique, we effectively depleted cyclin B1 mRNA in rat oocytes, thereby further ablating its protein product. Consequently, the oocytes were unable to activate MPF and remained meiotically arrested.

We herein report that in the absence of an active MPF the oocytes failed to elongate the c-mos mRNA poly(A) tail, did not accumulate Mos and were unable to activate MAPK. These results provide definitive evidence that the Mos/MAPK signal transduction pathway in rat oocytes is regulated by MPF.

\section{Materials and methods}

\section{Reagents and antibodies}

Leibovitz's L-15 tissue culture medium and Lipofectamine were purchased from Gibco BRL (Paisley, UK). Antibiotics were purchased from Bio-Lab Ltd (Jerusalem, Israel). PKI, isobutylmethylxantine (IBMX), N6, 2'-o-dibutyryladenosine $3^{\prime}: 5^{\prime}$-cyclic monophosphate (dibutyryl cyclic AMP, dbcAMP), Nonident P-40, $\beta$-glycerophosphate, PMSF, leupeptine, aprotonin, DTT, ethidium bromide, agarose and fetal bovine serum were purchased from Sigma. Affinity-purified polyclonal goat anti-Mos antibody, mouse anticyclin B1 and mouse anti-p34 cdc2 were purchased from Santa Cruz, Inc. (Santa-Cruz, CA, USA). Polyclonal rabbit anti-general MAPK (G-MAPK, Sigma) and monoclonal mouse anti-double-phosphorylated MAPK (DP-MAPK) were kindly provided by Prof. Rony Seger, Weizmann Institute of Science, Rehovot, Israel. Donkey antigoat, goat antimouse and goat antirabbit peroxidase-conjugated antibodies were purchased from Jackson ImmunoResearch Laboratories, Inc. (West Grove, PA, USA). $\left[\alpha-{ }^{32} \mathrm{P}\right] \mathrm{dATP},\left[\gamma_{-}{ }^{32} \mathrm{P}\right] \mathrm{ATP}$ and enhanced chemiluminescence (ECL) Western blotting detection reagents were purchased from Amersham. Roscovitine was purchased from Calbiochem (La Jolla, CA, USA). MEGASGRIPT-in vitro T7 transcription kit for large-scale synthesis of RNAs was purchased from Ambion (Austin, TX, USA).

\section{dsRNA preparation}

Total oocyte RNA was extracted by the RNasole method (Chomczynski \& Sacchi 1987) and reverse transcribed, using specific primers, followed by PGR amplification. RT reaction contained $50 \mathrm{U}$ of MMLV-RT, $200 \mu \mathrm{M}$ dNTP, $6.5 \mathrm{mM} \mathrm{MgCl}_{2}, 20 \mathrm{U}$ of RNasine, $500 \mathrm{ng}$ Oligo(dT) and 1.5 $\times$ RT buffer (Promega). The reaction was carried out at $37{ }^{\circ} \mathrm{C}$ for $2 \mathrm{~h}$. The PGR template method was used to synthesize dsRNA. Primers were chosen in order to amplify 650 bases region of exon sequences within the coding part of rat cyclin B1. The following pair of primers were employed: 5'-TGATACTCGCTC 
TCGAAG-3' and 5'-AATGCACGATGTCGT ATG-3'. The 5' ends of each primer corresponded to a 27 nucleotide $\mathrm{T} 7$ promoter sequence (TAATACGACTCACTATAGGGAGACGAC). PCR reaction was further performed in the same RT test tube that finally contained $250 \mathrm{ng}$ of each primer, $200 \mu \mathrm{M}$ dNTP, $2.5 \mathrm{mM} \mathrm{MgCl} 2,1 \times$ PCR buffer (Promega) and $2.5 \mathrm{U}$ Taq polymerase. Thirty cycles were conducted after a 5-min incubation at $95{ }^{\circ} \mathrm{C}$ as follows: $95^{\circ} \mathrm{C}$ for $5 \mathrm{~min}$; $95{ }^{\circ} \mathrm{C}$ for $1 \mathrm{~min}, 62{ }^{\circ} \mathrm{C}$ for $1.5 \mathrm{~min}$, and $72{ }^{\circ} \mathrm{C}$ for $2 \mathrm{~min}$. This was followed by a final extension for $10 \mathrm{~min}$. The PGR products were phenol/ chloroform extracted and ethanol precipitated in $\mathrm{NH}_{4} \mathrm{OAc}$. The precipitate was dissolved in autoclaved, double-distilled water, and the concentration was measured spectrophotometrically. dsRNA synthesis reaction was performed with the MEGASGRIPT-in vitro $\mathrm{T} 7$ transcription kit for large-scale synthesis of RNAs (Ambion, Austin, TX, USA), according to the instruction manual. Following an overnight incubation, DNA template was removed with DNase 1 (2 U) for $15 \mathrm{~min}$ at $37^{\circ} \mathrm{C}$. To stop the reaction, LiCl precipitation solution $(7 \cdot 5 \mathrm{M})$ was added to the RNA for $30 \mathrm{~min}$ at $-20{ }^{\circ} \mathrm{C}$. The precipitate was centrifuged at $4{ }^{\circ} \mathrm{C}$ for $15 \mathrm{~min}$, at maximum speed, to obtain the RNA pellet. The supernatant was removed carefully. The pellet was washed with $70 \% \mathrm{EtOH}$ and recentrifuged to maximize removal of unincorporated nucleotides. The wash solution was removed carefully, and RNA was resuspended in autoclaved, double-distilled water. The presence of dsRNAs was confirmed by ribonuclease protection assay.

\section{Ribonuclease protection assay}

Volumes of $350 \mu$ l digestion buffer (300 mM NaAc, $10 \mathrm{mM}$ Tris, $5 \mathrm{mM}$ EDTA), $4 \mu \mathrm{g}$ RNase A and $4 \mathrm{U}$ RNase T1 were added to each sample. After 1-h incubation at $30{ }^{\circ} \mathrm{C}, 10 \mu \mathrm{l}$ of $20 \%$ SDS and $2.5 \mu \mathrm{l}$ of $10 \mathrm{mg} / \mathrm{ml}$ proteinase $\mathrm{K}$ were added, and the samples were incubated for $20 \mathrm{~min}$ at $37^{\circ} \mathrm{C}$. The products were extracted with $400 \mu \mathrm{l}$ of phenol/chloroform/isoamyl alcohol (25:24:1). The supernatant was transferred into $1 \mathrm{ml} \mathrm{100 \%} \mathrm{EtOH}$ and $10 \mu \mathrm{g}$ of glycogen and incubated at $-70{ }^{\circ} \mathrm{C}$ for $30 \mathrm{~min}$. Samples were centrifuged for $15 \mathrm{~min}$, EtOH was aspirated and pellets were allowed to dry. The pellets were resuspended in $8 \mu \mathrm{l}$ of formamide-based loading dye and electrophoresed on $1 \%$ ethidium bromide agarose gel. Single-strand RNA synthesized with the MEGASCRIPT T7 in vitro transcription kit from control template (linearized TRIPLEscript plasmid containing $1.85 \mathrm{~kb}$ Xenopus elongation factor $1 \alpha$ gene under transcriptional control of tandem $\mathrm{T} 7$ promoters, pTRI-Xefl) served as a positive control.

\section{Oocyte recovery and treatment}

The physiological trigger for reinitiation of meiosis in mammalian oocytes is provided by the preovulatory surge of luteinizing hormone (LH) (Tsafriri et al. 1972, Tsafriri \& Dekel 1994). However, when oocytes are removed from the ovarian follicles and placed in culture, meiosis resumption occurs spontaneously in the absence of gonadotropins (Pincus \& Enzmann 1935). These spontaneously maturing oocytes were employed in our study.

The oocytes were recovered from 23-day-old Wistar female rats injected subcutaneously with 10 IU pregnant mare's serum gonadotropin (PMSG, Chrono-gest Intervest, Oss, The Netherlands) and killed $48 \mathrm{~h}$ later. The ovaries were removed and preovulatory cumulus-oocyte complexes were isolated into Leibovitz L-15 tissue culture medium containing 10\% fetal bovine serum. The cumulusoocytes complexes were then incubated in an acidic L-15 medium $(\mathrm{pH}=6 \cdot 0)$ to remove the cumulus cells and obtain cumulus-free oocytes.

For dsRNA transfection, the zona pellucida (ZP) was removed by incubation in acid Tyrode's solution $(\mathrm{pH}=3 \cdot 5)$ for a few seconds, followed by several washings in a large volume of L-15 tissue culture medium. Meiotically arrested oocytes, incubated in the presence of dbcAMP $(2 \mathrm{mM})$ and IBMX $(20 \mu \mathrm{M})$ were transfected by purified dsRNA (33 ng/ $\mathrm{ll})$, using cationic liposomes $(35 \mu \mathrm{g} / \mathrm{ml})$. Cationic liposomes devoid of dsRNA were employed to generate the control oocytes. After $7 \mathrm{~h}$, the oocytes were transferred to inhibitor-free medium for an additional incubation time. The oocytes were then subjected to Western blot analysis and RT-PCR.

Other oocytes were incubated for the indicated times in a humidified incubator at $37^{\circ} \mathrm{C}$. These oocytes were examined morphologically for the presence of GV with a StereoZoom 5 Pod microscope (Bosh and Lomb, Rochester, NY, USA). For DNA staining, the oocytes were incubated with live 
cells nucleic acid stain, syto-11 (Molecular Probes, Eugene, OR, USA, 1:1000) for $1 \mathrm{~h}$ at room temperature. These oocytes were visualized by a laser scanning confocal system (BioRad) connected to a Nikon (TE-300) inverted microscope.

The experiments were conducted in accordance with the Guide for the Care and Use of Laboratory animals (National Research Council, National Academy of Science, Bethesda, MD, USA).

\section{Western blot analysis}

Samples of oocytes were extracted in a lysis buffer ( $\beta$-glycerophosphate $50 \mathrm{mM}$, EGTA $1.5 \mathrm{mM}$, EDTA $1 \mathrm{mM}$, sodium-o-vanadate $0.1 \mathrm{mM}$, benzamidine $1 \mathrm{mM}$, aprotonine $10 \mu \mathrm{g} / \mathrm{ml}$, leupeptine $10 \mu \mathrm{g} / \mathrm{ml}$, pepstatine A $2 \mu \mathrm{g} / \mathrm{ml}$, DTT $1 \mathrm{mM}$, PMSF $1 \mathrm{mM}$ ), and Laemmli sample buffer (Laemmli 1970) was added. The samples were boiled and loaded on 12\% SDS-PAGE, followed by their transfer to a nitrocellulose membrane. Following blocking with TTBS, containing 10\% skim milk, the membranes were incubated with the relevant antibodies. The following antibodies were used: affinity-purified polyclonal goat anti-Mos antibody (1:500 dilution), rabbit anti-general MAPK (G-MAPK, 1:5000 dilution), mouse anti-doublephosphorylated MAPK (DP-MAPK, 1:5000 dilution) (Yung et al. 1997), mouse anti-cyclin B1 (1:250 dilution) and mouse anti-p34 cdc2 (1:500 dilution). Donkey antigoat, goat antirabbit and goat antimouse HRP-conjugated second antibodies (1:5000 dilution) were used as second antibodies. The immunoreactive bands were detected by enhanced chemiluminescence (ECL) reagents. Quantitation of the autoradiograms was performed by densitometric analysis using the 420oe densitometer (Pdi, Huntington Station, NY, USA).

\section{H1 kinase activity}

Histone $\mathrm{H} 1$ activity was determined as described previously (Josefsberg et al. 2003). Briefly, lysates of 50 oocytes were prepared by freezing and thawing in $10 \mu \mathrm{l}$ kinase buffer $(15 \mathrm{mM} 3-(\mathcal{N}$-morpholino)propanesulfonic acid (MOPS), $80 \mathrm{mM} \beta$-glycerophosphate, $10 \mathrm{mM}$ EGTA, $15 \mathrm{mM} \mathrm{MgCl}_{2}, 0 \cdot 1 \mathrm{mM}$ PMSF, $10 \mu \mathrm{g} / \mathrm{ml}$ leopeptin, $10 \mu \mathrm{g} / \mathrm{ml}$ aprotonin, $10 \mu \mathrm{g} / \mathrm{ml}$ PKI, a cAMP-dependent protein kinase inhibitor peptide). Kinase reactions were initiated by the addition of $10 \mu \mathrm{l}$ substrate buffer $(2 \mathrm{mg} / \mathrm{ml}$ histone $\mathrm{Hl}, 2 \mathrm{mM}$ dithiothreitol (DTT), $5 \mu \mathrm{Ci}$ $\left.\left[\gamma-{ }^{32} \mathrm{P}\right] \mathrm{ATP}\right)$, and the reactions were carried out at $30{ }^{\circ} \mathrm{C}$ for $40 \mathrm{~min}$. Kinase reaction products were subjected to SDS-PAGE and autoradiography.

\section{RT-PCR}

The p34 cdc2, S16, and c-mos mRNA levels were detected by RT-PCR. For this purpose, total oocyte mRNA was extracted by the acid-guanidinum-phenol/chloroform method (Chomczynski \& Sacchi 1987) and reverse transcribed before PCR amplification by specific primers. RT reaction contained $50 \mathrm{U}$ of Moloney murine leukemia virus-reverse transcriptase, $200 \mu \mathrm{M}$ deoxynucleotide triphosphates (dNTPs), $6.5 \mathrm{mM} \mathrm{MgCl}_{2}, 20 \mathrm{U}$ ribonuclease inhibitor, $500 \mathrm{mg}$ Oligo(dT) and 1.5 $\times$ PCR buffer (Promega). The reaction was carried out at $37^{\circ} \mathrm{C}$ for $2 \mathrm{~h}$. Fragments of the reverse-transcribed indicated genes were amplified, and the following pairs of primers were employed: for c-mos gene amplification, 5'-GCACGACGACAACATAATCG-3', and 5'-CAGCGGAAGTCACTTATCTTAC-3'; for S-16 gene amplification, 5'-cgttcaccttgatgagccc att- $3^{\prime}$ and $5^{\prime}$-tccaagggtccgctgcagtc- $3^{\prime}$; for cyclin B1 gene amplification, 5'-TGATACTCCCTCTCG AAGGG-3' ${ }^{\prime}$ and 5'-AATGGACGATGTGGTAG TCG-3'; for p34 cdc2 amplification, 5'-AAA GCGAGGAAGAAGGAGTGCG-3' and 5'-AGT CGAAGCGGTTTTCATCGAG-3'.

PCR reactions were further performed in the same RT test tube that finally contained $250 \mathrm{ng}$ of each primer, $200 \mu \mathrm{M}$ dNTP, $2.5 \mathrm{mM} \mathrm{MgCl}_{2}$ $1 \times$ PGR buffer and $2.5 \mathrm{U}$ Taq polymerase (Promega). Thirty and 28 cycles for S-16 and c-mos respectively were performed after 2-min incubation at $94{ }^{\circ} \mathrm{C}$ as follows: $94{ }^{\circ} \mathrm{C}$ for $30 \mathrm{~s} ; 60{ }^{\circ} \mathrm{C}$ for $30 \mathrm{~s}$ and $72^{\circ} \mathrm{C}$ for $1 \mathrm{~min}$. This was followed by a final extension for $5 \mathrm{~min}$ at $72^{\circ} \mathrm{C}$. Thirty cycles for cyclin B1 and p34 cdc2 were performed after a 5-min incubation at $95^{\circ} \mathrm{C}$ as follows: $95^{\circ} \mathrm{C}$ for $5 \mathrm{~min} ; 62{ }^{\circ} \mathrm{C}$ for $1.5 \mathrm{~min}$ and $72{ }^{\circ} \mathrm{C}$ for $2 \mathrm{~min}$. This was followed by a final extension for $10 \mathrm{~min}$ at $72{ }^{\circ} \mathrm{C}$. The products were electrophoresed on $1 \%$ ethidium bromide agarose gel.

\section{Analysis of c-mos mRNA polyadenylation}

c-mos mRNA polyadenylation was detected by the polymerase chain reaction (PCR), as described by 
Lazar et al. (2002). Briefly, total oocyte RNA was extracted by the RNasole method (Chomczynski \& Sacchi 1987). An aliquot of RNA in $\mathrm{H}_{2} \mathrm{O}$ (equivalent to $100-150$ oocytes) was heat-denatured $\left(65^{\circ} \mathrm{C}\right.$ for $5 \mathrm{~min}$ ) in a $7 \mu \mathrm{l}$ volume in the presence of $20 \mathrm{ng}$ phosphorylated Oligo(dt) (Promega) and placed directly at $42{ }^{\circ} \mathrm{C}$. Prewarmed mastermix (13 $\mu$ l containing $4 \mu \mathrm{l}$ of $5 \mathrm{X}$ Superscript $\mathrm{RNase} \mathrm{H}^{-}$reverse transcriptase (RT) buffer (Gibco BRL Paisley, UK), $2 \mu \mathrm{l}$ of $0 \cdot 1 \mathrm{M}$ DTT, $1 \mu \mathrm{l}$ of $10 \mathrm{mM}$ dNTPs, $1 \mu \mathrm{l}$ of $10 \mathrm{mM}$ ATP, $4 \mu \mathrm{l}$ of $\mathrm{H}_{2} \mathrm{O}$ and $1 \mu \mathrm{l}$ of $10 \mathrm{U} / \mu \mathrm{l} \mathrm{T} 4$ DNA ligase)) was added, and the samples were incubated at $42{ }^{\circ} \mathrm{C}$ for $30 \mathrm{~min}$. Subsequently, $1 \mu \mathrm{l}$ Oligo(dt)-anchor (200 ng/ $\mu \mathrm{l}, 5^{\prime}$-GCGAGCTCGG CGGCGGCGT12-3') was added at $42{ }^{\circ} \mathrm{C}$, and the reaction was transferred to a $12{ }^{\circ} \mathrm{C}$ water bath. After 2-h incubation, the samples were transferred back to $42{ }^{\circ} \mathrm{C}, 2 \mu \mathrm{l}(200 \mathrm{U} / \mu \mathrm{l})$ Superscript RNase $\mathrm{H}^{-} \mathrm{RT}$ was added (Gibco BRL), and reverse transcription (RT) was performed for $1 \mathrm{~h}$. cDNAs were diluted to 6 oocytes/ $\mu$ l, followed by 30-min incubation at $70{ }^{\circ} \mathrm{C}$ to inactivate the RT and the ligase. For PCR amplification, $1 \mu \mathrm{l} \mathrm{cDNAs}$ was added to a standard $50 \mu \mathrm{l}$ PCR reaction spiked with $0 \cdot 5 \mu \mathrm{l}\left[\alpha_{-}{ }^{32} \mathrm{P}\right] \mathrm{dATP}$ and containing 25 pmoles each of Mos mRNA specific primer (5'-GCACCACGACAACATAA TCC- $3^{\prime}$ ) and the Oligo(dt)-anchor (amplification conditions: $93{ }^{\circ} \mathrm{C}$ for $5 \mathrm{~min} ; 30$ cycles at $93{ }^{\circ} \mathrm{C}$ for $30 \mathrm{~s} ; 62{ }^{\circ} \mathrm{C}$ for $1 \mathrm{~min} ; 72{ }^{\circ} \mathrm{C}$ for $1 \mathrm{~min}$; with a final extension of $7 \mathrm{~min}$ at $72{ }^{\circ} \mathrm{C}$ ). After amplification, PCR products were ethanol-precipitated with $2.5 \mathrm{M}$ ammonium acetate to remove unincorporated label. To confirm the specificity of the amplification and demonstrate that the increase of the PCR fragments was attributable to elongation of the $3^{\prime}$ end of the mRNA, samples were digested with XmnI (Promega). This treatment showed heterogeneous 3' ends. The radioactive products were electrophoresed on 5\% nondenaturing polyacrylamide gel in $0.5 \mathrm{X}$ TBE buffer. Gels were dried, and radioactivity was determined by their exposure to radiographic film overnight.

\section{Results}

\section{Preparation of a cyclin B1 dsRNA}

Roscovitine, a selective potent inhibitor of p34 cdc2 kinase (Meijer \& Kim 1997), has been recently shown to prevent c-mos mRNA polyadenylation (Lazar et al. 2002) and abolish Mos expression

\section{RNase treatment}

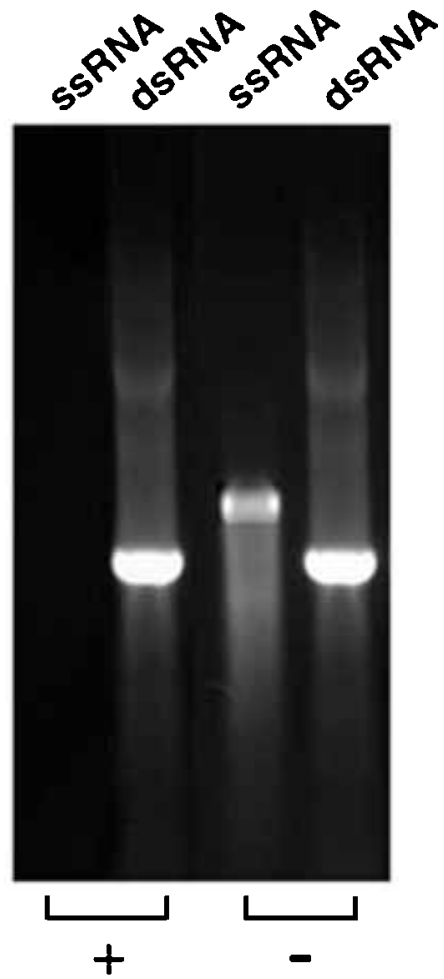

Figure 1 Ribonuclease protection assay. The purified cyclin B1 dsRNA was tested by the RNase protection assay. ssRNA (linearized TRIPLEscript plasmid containing $1.85 \mathrm{~kb}$ Xenopus elongation factor $1 \alpha$ gene under transcriptional control of tandem T7 promoters, pTRI-Xef1), which was synthesized with the in vitro transcription kit, served as positive control for this assay. The results of one representative experiment out of three repetitions are presented.

(Josefsberg et al. 2002). Roscovitine does not interfere solely with p34 cdc2 kinase activity, but rather competes with ATP binding in a variety of protein kinases (Meijer et al. 1997). In the present study, to prove that MPF participates in regulation of Mos expression, we employed dsRNAi, which was targeted at the expression of cyclin B1 mRNA. For this purpose, cyclin B1 dsRNA was generated by in vitro transcription of cyclin B1 template containing a $\mathrm{T} 7$ promoter sequence, and the products were subjected to ribonuclease protection assay. This assay confirmed that the in vitro transcription output is indeed dsRNA (Fig. 1).

\section{Specificity and efficiency of cyclin B1 RNAi in rat oocytes}

Cationic liposomes were employed for the introduction of the cyclin Bl dsRNA into oocytes that 
A

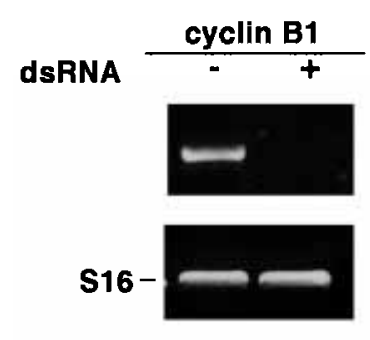

B
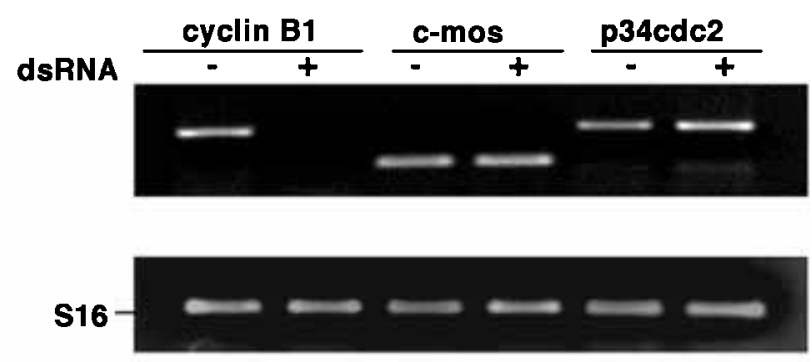

C

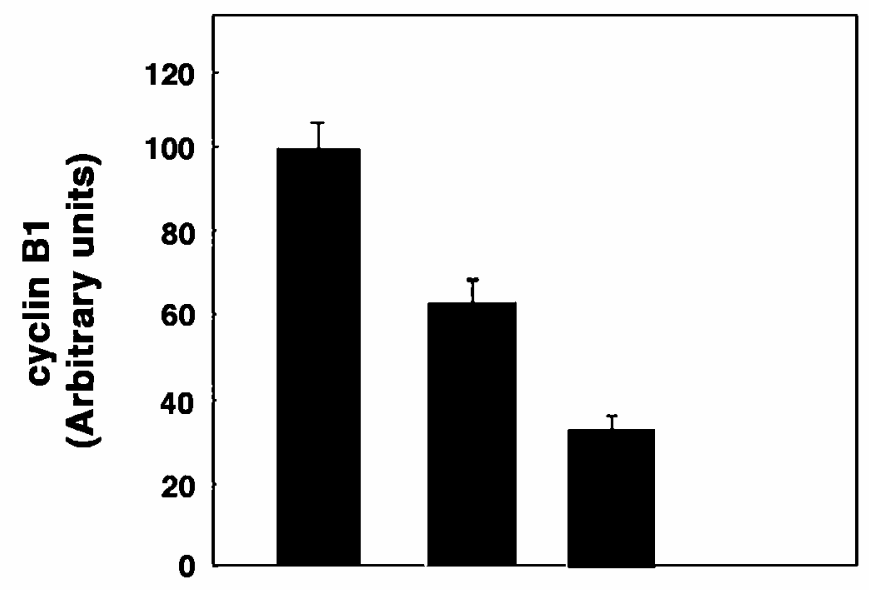

D
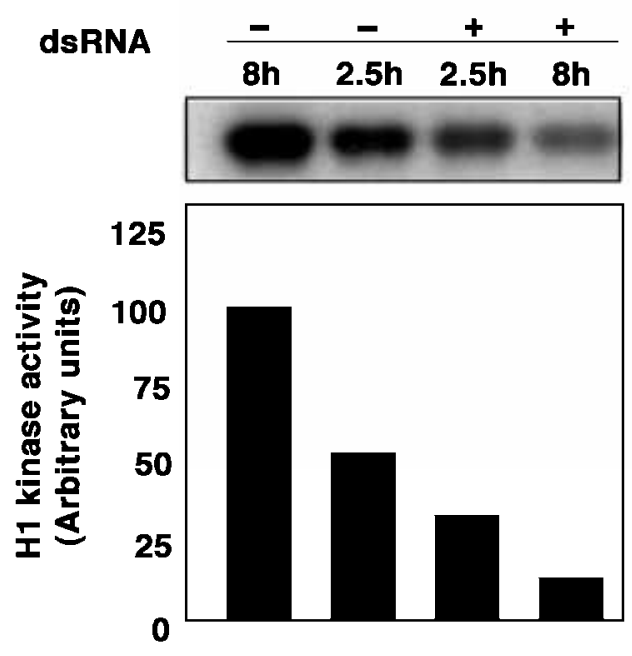

E

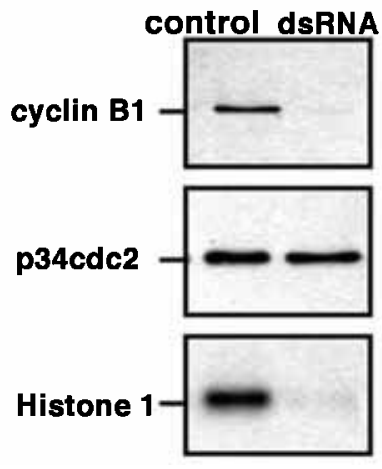


were maintained in meiotic arrest by dbcAMP and IBMX. To test the efficiency of transfection, these oocytes were examined for the expression of cyclin B 1 mRNA at different time points, after removal of the above-mentioned inhibitors. We found that cyclin B1 mRNA was totally eliminated in oocytes incubated for $2.5 \mathrm{~h}$ in an inhibitor-free medium (Fig. 2A). No detectable changes were observed in the c-mos and p34 cdc2 mRNAs, indicating that the destruction of cyclin B1 mRNA was highly specific (Fig. 2B). The consequences of interference of cyclin Bl dsRNA with its corresponding mRNA was further confirmed by Western blot analysis. This experiment revealed a substantial reduction in cyclin B1 at $2.5 \mathrm{~h}$, with a further decrease of the protein levels at $8 \mathrm{~h}$ (Fig. 2C). Full ablation of the cyclin $\mathrm{B} 1$ protein was observed after an additional $12 \mathrm{~h}$ of incubation (Fig. 2C).

Cyclin B1 is an essential component of an active MPF. Therefore, the absence of cyclin Bl was functionally examined by the $\mathrm{H} 1$ kinase assay. As shown in Fig. 2D, the ability of MPF to phosphorylate histone $\mathrm{Hl}$ at $2.5 \mathrm{~h}$ of incubation was lower in oocytes transfected with cyclin B1 dsRNA than in controls. The effect of dsRNA transfection on MPF activity was more pronounced at $8 \mathrm{~h}$, a time point at which MPF activity reaches its maximum (Josefsberg et al. 2003). Interestingly, activity of MPF could not be detected in oocytes transfected with cyclin Bl dsRNA, despite the comparable amounts of p34 cdc2 demonstrated in the experimental and control groups (Fig. 2E).

MPF activation, upon reinitiation of meiosis, induces GVB and chromosome condensation. The presence of GVB was monitored microscopically in

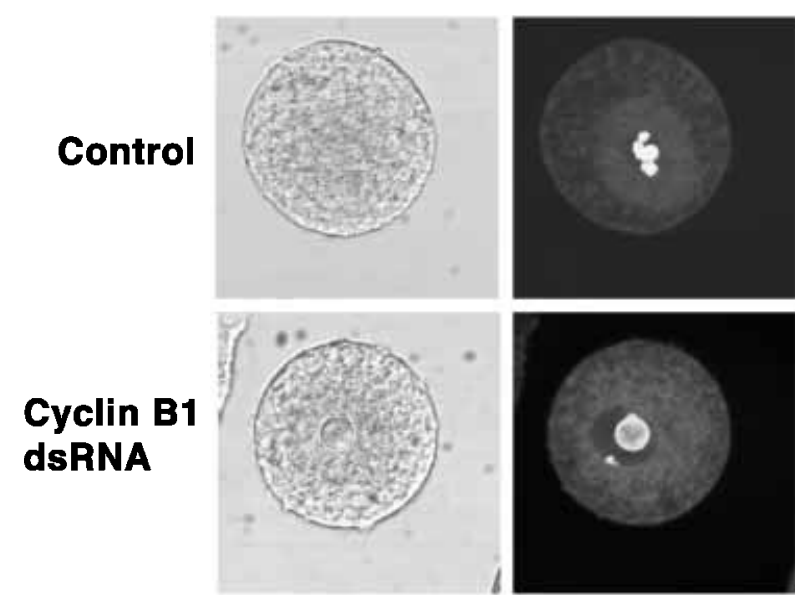

Figure 3 Effect of cyclin B1 dsRNA on the meiotic status of the oocyte. Oocytes incubated in the presence of dbcAMP $(2 \mathrm{mM})$ and IBMX $(20 \mu \mathrm{M})$ for $7 \mathrm{~h}$ were transfected with or without dsRNA (33 ng/ $\mu$ l), using cationic liposomes. After an additional incubation time of $8 \mathrm{~h}$ in inhibitor-free medium, DNA was stained with cyto 11 (1/1000), and the oocytes were examined by confocal microscopy. The results of one representative experiment out of three repetitions are presented.

both the experimental $(n=68)$ and control $(n=44)$ oocytes, and served as an additional functional parameter for the evaluation of the efficiency of cyclin B1 dsRNA transfection. This experiment was complemented by DNA staining. As expected, in the absence of an active MPF, $81 \%$ of the the cyclin B1 dsRNA-transfected oocytes failed to undergo GVB, and their chromatin stayed in its diffused configuration (Fig. 3). On the other hand, disappearance of the nuclear structure accompanied by chromosome condensation was

Figure 2 The effect of cyclin B1 dsRNA in rat oocytes. Oocytes incubated in the presence of dbcAMP (2 mM) and IBMX $(20 \mu \mathrm{M})$ for $7 \mathrm{~h}$ were transfected with dsRNA (33 $\mathrm{ng} / \mathrm{\mu l})$, using cationic liposomes. (A) Efficiency of cyclin B1 dsRNA transfection. RNA was extracted from oocytes (20 oocytes/lane) at $2.5 \mathrm{~h}$ after their incubation in inhibitor-free medium. RT-PCR was performed with specific primers for cyclin B1. The PCR product was analyzed by ethidium bromide agarose gel electrophoresis. The results of one representative experiment out of three repetitions are presented. (B) Specificity of cyclin B1 dsRNA transfection. RNA was extracted from oocytes (20 oocytes/lane) $8 \mathrm{~h}$ after their incubation in inhibitor-free medium. RT-PCR was performed with specific primers for cyclin B1, c-mos, p34 cdc2 and S16 mRNA. PCR products were analyzed by ethidium bromide agarose gel electrophoresis. The results of one representative experiment out of three repetitions are presented. (C) Effect of cyclin B1 dsRNA transfection on cyclin B1 protein. Western blot analysis was performed after 2.5 and $8 \mathrm{~h}$ of incubation in inhibitor-free medium, using specific antibodies against cyclin B1. The results of one representative experiment out of three repetitions are presented. (D) Effect of cyclin B1 dsRNA transfection on the activity of MPF. MPF activity was assayed in oocytes collected at 2.5 and $8 \mathrm{~h}$ of incubation in inhibitor-free medium. The results of one representative experiment out of three repetitions are presented. (E) Effect of cyclin B1 dsRNA transfection on the presence of p34 cdc2. Western blot analysis was performed after 20-h incubation in inhibitor-free medium, using specific antibodies against cyclin B1 and p34 cdc2. MPF activity was assayed by H1 kinase activity. The results of one representative experiment out of three repetitions are presented. 
clearly observed in 95\% of the control oocytes transfected by cationic liposomes devoid of dsRNA.

\section{Effect of cyclin B1 mRNA depletion on c-mos mRNA polyadenylation, Mos accumulation and MAPK activity}

Having established the successful depletion of the cyclin B1 mRNA, we further examined the oocytes for the length of their c-mos mRNA poly(A) tail. We previously reported that the c-mos mRNA in rat meiotically arrested oocytes possesses a poly(A) tail of $50 \mathrm{bp}$ that was elongated by about 300 bases towards the MI of meiosis (Lazar et al. 2002). Similarly, control oocytes that were allowed to resume meiosis in the present study expressed a c-mos mRNA poly(A) tail of about $350 \mathrm{bp}$ (Fig. 4A). On the other hand, the c-mos mRNA in the cyclin B1 dsRNA-transfected oocytes exhibited a poly(A) tail of only $50 \mathrm{bp}$, suggesting failure of polyadenylation under these conditions.

We further examined the oocytes for their capacity to translate the mos-mRNA and accumulate its protein product by Western blot analysis. This experiment could not detect Mos in the cyclin B1 dsRNA-transfected oocytes (Fig. 4B). Since Mos is the upstream regulator of MAPK, our assumption was that the absence of Mos would be further manifested by the failure of the oocytes to activate MAPK. Indeed, depletion of cyclin B1 resulted in the absence of the phosphorylated, active form of MAPK (Fig. 4C).

\section{The MPF-sensitive window for Mos translation}

Activation of MPF in rat oocytes is intially observed at $2 \mathrm{~h}$ after the onset of meiosis and reaches its maximum at $8 \mathrm{~h}$ (Josefsberg et al. 2003). However, the presence of Mos in these oocytes could not be detected until $6 \mathrm{~h}$ after the reinitiation of meiosis (Lazar et al. 2002). In order to define the MPF-sensitive window for c-mos mRNA polyadenylation and Mos accumulation, we used the following experimental strategy: freshly isolated oocytes were incubated for different time periods, which allowed for the initial stages of MPF activation. The oocytes were then transferred into medium containing roscovitine for cessation of p34 cdc2 kinase activity. After the total incubation time of $8 \mathrm{~h}$, the oocytes were analyzed for c-mos mRNA polyadenylation and the presence of Mos. We
A

\section{Poly(A) \\ length control dsRNA}

B

control dsRNA
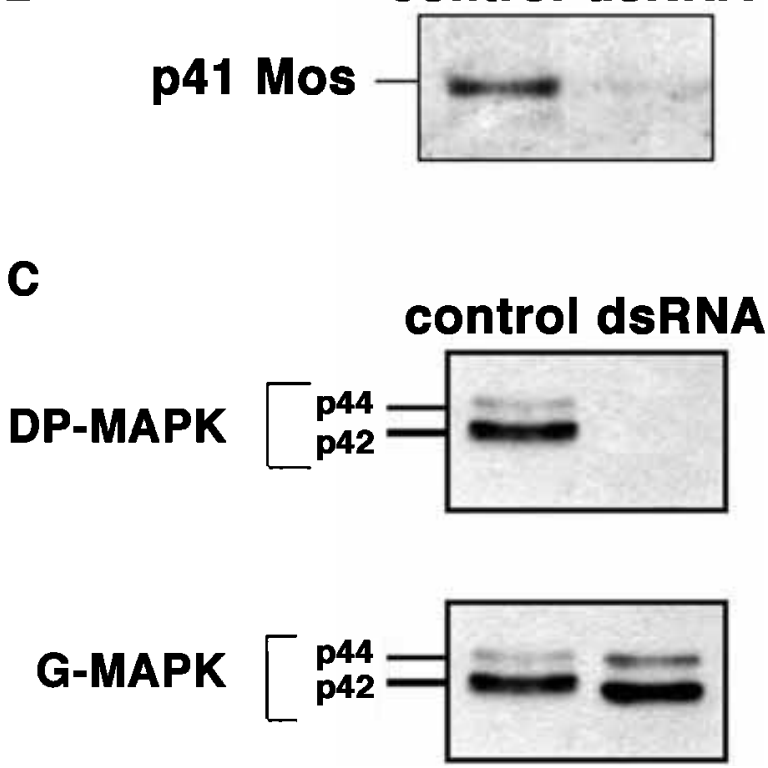

Figure 4 Effect of cyclin B1 dsRNA on c-mos mRNA polyadenylation, Mos expression and MAPK activation. Oocytes incubated in the presence of dbcAMP $(2 \mathrm{mM})$ and IBMX $(20 \mu \mathrm{M})$ for $7 \mathrm{~h}$ were transfected with or without dsRNA (33 $\mathrm{ng} / \mathrm{\mu l}$ ), using cationic liposomes. After an additional $20 \mathrm{~h}$ of incubation in inhibitor-free medium, the oocytes were subjected to poly $(A)$ tail analysis (PAT) of c-mos mRNA (A), Western blot analysis with anti-Mos antibodies (B), and Western blot analysis with specific antibodies against DP-MAPK and G- MAPK (C). The results of one representative experiment out of three repetitions are presented. 
found that at least $3 \mathrm{~h}$ of incubation in roscovitinefree medium are required for the elongation of the c-mos mRNA poly(A) tail (Fig. 5A) and the subsequent expression of Mos (Fig. 5B). Elevated activity of MPF, generated for a shorter time

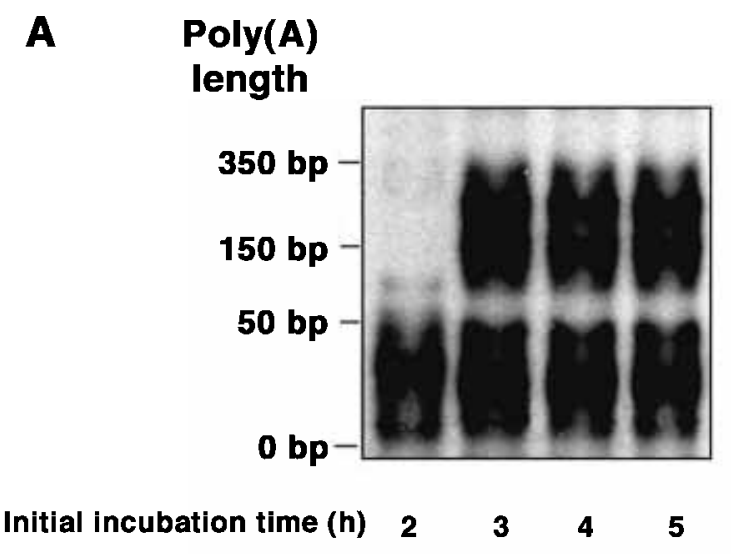

$\mathbf{B}$

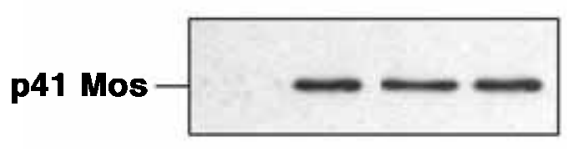

$\begin{array}{lllll}\text { Initial incubation time (h) } & 2 & 3 & 4 & 5\end{array}$

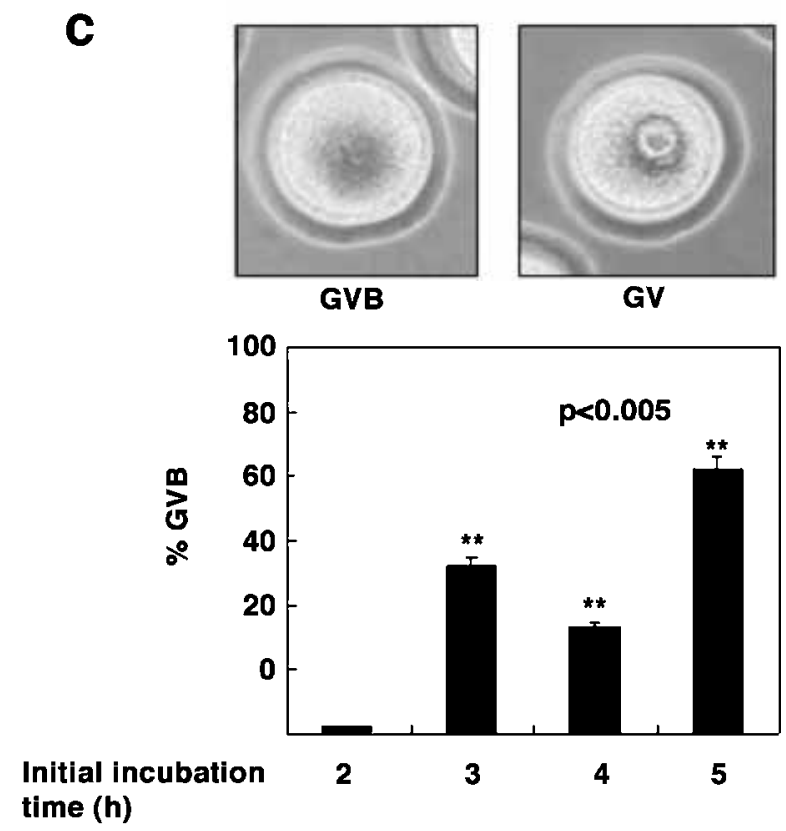

www.endocrinology.org interval, is apparently insufficient to allow mos translation (Fig. 5B). A substantial elevation in the fraction of oocytes with an intact GVB, monitored between 2 and $3 \mathrm{~h}$ of incubation in roscovitine-free medium (Fig. 5C), suggests that a similar MPFsensitivity window applies to the dissolution of the nuclear structure; this is the first morphologic marker for oocyte maturation.

\section{Discussion}

We herein report the first successful dsRNAmediated interference with cyclin B1 mRNA. This efficient and specific ablation of cyclin $\mathrm{B} 1$ gene expression was followed by a time-dependent elimination of the cyclin $\mathrm{B} 1$ protein. As a result, the oocytes failed to activate MPF and remained meiotically arrested. We employed this experimental model to prove that rat oocytes unable to activate MPF will not promote c-mos mRNA cytoplasmic polyadenylation and its subsequent translation. As anticipated, these oocytes failed to activate MAPK.

In a previous attempt to shed light on the specific role of cyclin B1 in vertebrate cells, the classical technique of gene 'knockout' was employed (Brandeis et al. 1998). However, this experimental approach that eliminated the gene function universally resulted in embryonic lethality, failing to generate the information of interest. A later study, which used the antisense strategy specifically to ablate cyclin B1, demonstrated its dispensability at entry into M-phase in Xenopus oocytes (Hochegger et al. 2001). The dsRNA-mediated RNAi, directed at destruction of cyclin B1 mRNA in individual rat oocytes employed in the present

Figure 5 The MPF-sensitive window for c-mos mRNA polyadenylation, Mos translation and GVB. Freshly isolated oocytes (500/lane) were exposed to roscovitine-free medium for the indicated periods of time. The oocytes were then transferred into medium containing roscovitine $(100 \mu \mathrm{M})$ for further incubation. After a total incubation time of $8 \mathrm{~h}$, poly $(\mathrm{A})$ tail analysis (PAT) of c-mos mRNA (A) and Western blot analysis, using anti-Mos antibodies (B), were performed. The results of one representative experiment out of three repetitions are presented. Another group of the above oocytes were monitored for the presence of GVB (C). Means \pm standard errors of quantitative analysis of three experiments are presented. 
study, allowed full clarification of the role of this gene at the $\mathrm{G} 2 / \mathrm{M}$ transition of meiosis in mammals.

Genetic and biochemical studies suggest that the RNAi pathways evolved as a defense against RNA viruses or transposones, possibly before plants and animals diverged. This phenomenon, first described less than two decades ago (Marcus 1983), allows targeted genes to be efficiently silenced, revolutionizing functional genomics. This experimental approach has been previously shown to ablate targeted mRNA in lower organisms such as Caenorhabditis elegans (Fire et al. 1998, Montgomery et al. 1998, Fire 1999), zebrafish (Li et al. 2000) and Drosophila (Kenerdell \& Carthew 1998, Tuschl et al. 1999, Hammond et al. 2000). Specific interference of gene function by dsRNA treatment has only recently been achieved in mice (Svoboda et al. 2000, Wianny \& Zernicka-Goetz 2000). In view of the fact that mammalian cells typically respond to dsRNA accumulation after viral infection, by an overall block of translation (Lee \& Esteban 1994), the successful demonstration of RNAi in the mouse was somewhat surprising. This success may be attributed, at least in part, to the lack of such a response in oocytes and the early embryonic stages that served as experimental models in these studies.

Maturing oocytes are known to be transcriptionally dormant. Protein synthesis in these oocytes is enhanced by recruitment of pooled mRNA and its selective cytoplasmic polyadenylation (reviewed by Colgan \& Manley 1997). Unlike previous studies that chose to ablate dormant mRNAs prior to their translation (Svoboda et al. 2000, Wianny \& Zernicka-Goetz 2000), the cyclin Bl mRNA that was targeted in our study was translated, and the G2-arrested oocytes expressed a certain amount of its protein product. Our strategy took into account the oscillatory pattern of cyclin B1 accumulation that is regulated by a modulated balance between its synthesis and degradation (Winston 1997). We had postulated that interference with cyclin B1 translation would shift this balance, eventually resulting in protein elimination. Our experimental protocol was designed to allow the degradation of the pre-existing cyclin B1 in oocytes, maintained throughout transfection in a state of meiotic arrest by their incubation in dbcAMP/MIX. The removal of these inhibitors allowed control oocytes to resume meiosis spontaneously. However, the cyclin B1 dsRNA-transfected oocytes that had their corresponding mRNA ablated did not translate cyclin B1, failed to activate MPF and remained meiotically arrested.

We have previously shown that MPF activity in rat oocytes is elevated immediately after meiosis reinitiation (Josefsberg et al. 2003), whereas the accumulation of Mos is substantially delayed (Lazar et al. 2002). The relatively extended time interval that elapses between the initial increase in MPF action and c-mos mRNA translation may raise some concerns with regard to the direct correlation between these two events. By transiently exposing rat oocytes to a roscovitine-free medium, followed by their transfer into medium containing this p34 cdc2 inhibitor, we defined the MPF-sensitive window for Mos translation. This experiment revealed that the level of MPF activity generated at $3 \mathrm{~h}$, rather than at $2 \mathrm{~h}$ after meiosis reinitiation, allowed the elongation of the c-mos mRNA poly(A) tail and the subsequent expression of Mos. There was a substantial increase in the fraction of oocytes undergoing GVB after $3 \mathrm{~h}$ of incubation in roscovitine-free medium; this suggested that the dissolution of the nuclear membrane, which is the hallmark of the resumption of meiosis, exhibited a similar range of sensitivity to MPF. The kinetic analysis of cyclin Bl depletion in the dsRNAtransfected oocytes demonstrated that this experimental modification did indeed take place within the MPF-sensitive window for c-mos mRNA polyadenylation and Mos expression.

The inhibitory action of cAMP on the resumption of meiosis is well established (Cho et al. 1974, Dekel \& Beers 1978, 1980). This negative effect of cAMP, shown to inhibit the activation of the two key regulators of meiosis, MPF (Choi et al. 1991, Goren \& Dekel 1994) and MAPK (Lazar et al. 2002), raises the question of whether these enzymes operate independently, in parallel, or sequentially. Attempts to disclose the sequential order of these two enzymes, made in amphibians as well as murine oocytes, produced conflicting results (reviewed by Castro et al. 2001). Generation of the Mos-deficient mouse model (Colledge et al. 1994, Hashimoto et al. 1994) suggested that, at least in rodent oocytes, MPF activation is independent of the Mos/MAPK signaling pathway (Hashimoto 1996), leaving the option of a reverse sequential order open. We clearly show that MPF activation is an essential precondition for c-mos mRNA polyadenylation, Mos translation and MAPK activation. A different experimental 
CAMP

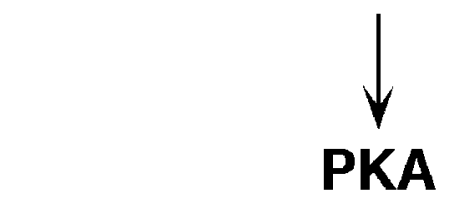

pre MPF $\stackrel{\perp}{\longrightarrow}$ MPF inactive

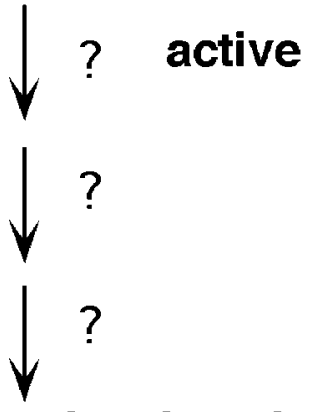

C-mos mRNA polyadenylation
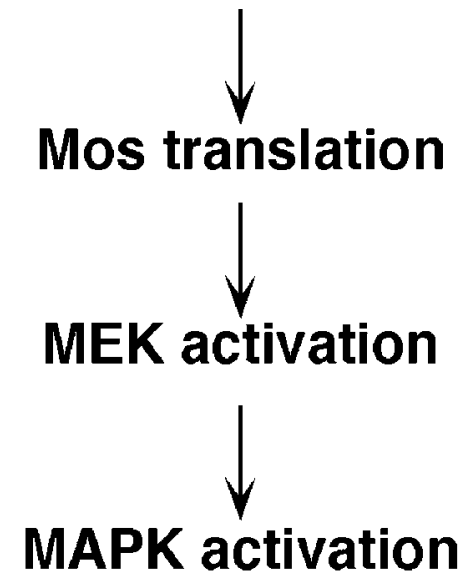

Figure 6 A proposed model for regulation of Mos expression in rat oocytes resuming meiosis. The transition of the inactive pre-MPF into the active MPF is suppressed by active PKA. Upon the drop of intraoocyte concentration of CAMP at reinitiation of meiosis, PKA becomes inactive and MPF is activated. The active MPF induces c-mos mRNA polyadenylation and subsequent Mos translation. The signal is transmitted to MEK, which activates MAPK.

approach that we previously employed also suggested that MAPK activation is governed by MPF (Josefsberg et al. 2003). These findings, combined with our previous report of a PKA-mediated cAMP inhibition of c-mos mRNA polyadenylation (Lazar et al. 2002), establish the hirearchy of the molecular events that reinitiate meiosis in oocytes as follows: the meiosis reinitiation-associated drop in intraoocyte concentrations of cAMP leads to an inactivation of PKA that allows the transition of the inactive pre-MPF into active MPF (Duckworth et al. 2002). Elevated activity of MPF switches on the cascade of events, although yet unresolved, that recruit c-mos mRNA for the polyadenylation inducing Mos translation. This accumulated Mos further stimulates MEK, which, in turn, upregulates the activity of MAPK (Fig. 6).

\section{Acknowledgements}

This work was supported by the Dwek Fund for Study of Fertility. ND is the incumbent of the Phillip M. Klutznick Professorial Chair for Developmental Biology. We thank Ms Martie Spiegel for editing the manuscript of this study.

\section{References}

Araki K, Naito K, Haraguchi S, Suzuki R, Yokohama M, Inoue M, Aizawa S, Toyoda Y \& Sato E 1996 Meiotic abnormalities of c-mos knockout mouse oocytes: activation after first meiosis or entrance into third meiotic metaphase. Biology of Reproduction $\mathbf{5 5}$ 1313-1324.

Bornslaeger EA, Mattei P \& Shultz RM 1986 Involvement of cAMP-dependent protein kinase and protein phosphorylation in regulation of mouse oocyte maturation. Developmental Biology 114 453-462.

Brandeis M, Rosewell I, Carrington M, Crompton T, Jacobs MA, Kirk J, Gannon J \& Hunt T 1998 Cyclin B2-null mice develop normally and are fertile whereas cyclin B1-null mice die in utero. PNAS $954344-4349$.

Castro N, Peter M, Lorca T \& Mandart E 2001 c-Mos and cyclin B/cdc2 connections during Xenopus oocyte maturation. Biology of the Cell 93 15-25.

Cho WK, Stern S \& Biggers JDB 1974 Inhibitory effect of dibutyryl cAMP on mouse oocyte maturation in vitro. Fournal of Experimental Zoology 187 383-386.

Choi T, Aoki F, Mori M, Yamashita M, Nagahama Y \& Kohmoto K 1991 Activation of p34 cdc2 protein kinase activity in meiotic and mitotic cell cycles in mouse oocytes and embryos. Development $113789-795$.

Choi T, Fukasawa K, Zhou R, Tessarollo L, Borror K, Resau J \& Vande Woude GF 1996 The Mos/mitogen-activated protein kinase (MAPK) pathway regulates the size and degradation of the first polar body in maturing mouse oocytes. PNAS 93 7032-7035.

Chomczynski P \& Sacchi N 1987 Single-step method of RNA isolation by acid guanidinium thiocyanate-phenol-chloroform extraction. Analytical Biochemistry 162 156-159.

Colgan DF \& Manley JL 1997 Mechanism and regulation of mRNA polyadenylation. Genes and Development 11 2755-2766.

Colledge WH, Carlton GB, Udy GB \& Evans MJ 1994 Disruption of c-mos causes parthenogenetic development of unfertilized mouse eggs. Nature 370 65-68. 
Culp PA \& Musci TJ 1999 c-mos and cdc2 cooperate in the translational activation of fibroblast growth factor receptor-1 during Xenopus oocyte maturation. Molecular Biology of the Cell $\mathbf{1 0}$ 3567-3581.

Dekel N 1996 Protein phosphorylation/dephosphorylation in the meiotic cell cycle of mammalian oocytes. Reviewes of Reproduction $\mathbf{1}$ 82-88.

Dekel N \& Beers WH 1978 Rat oocyte maturation in vitro: relief of cyclic AMP inhibition by gonadotropins. PNAS 75 4369-4373.

Dekel N \& Beers WH 1980 Development of the rat oocyte in-vitro: inhibition and induction of maturation in the presence or absence of the cumulus oophorus. Developmental Biology 75 247-254.

Duckworth BC, Weaver JS \& Ruderman JV 2002 G2 arrest in Xenopus oocytes depends on phosphorylation of cdc25 by protein kinase A. PNAS 99 16794-16799.

Duncan T, Sohail M \& Hunt T 2001 New B-type cyclin synthesis is required between meiosis I and II during Xenopus oocyte maturation. Development 128 3795-37807.

Dupre A, Jessus C, Ozon R \& Haccard O 2002 Mos is not required for the initiation of meiotic maturation in Xenopus oocytes. EMBO fournal 21 4026-4036.

Ferrell JE Jr, Wu M, Gerhart JC \& Martin GS 1991 Cell cycle tyrosine phosphorylation of p34 cdc2 and a microtubuleassociated protein kinase homolog in Xenopus oocytes and eggs. Molecular and Cellular Biology 11 1965-1971.

Fire A 1999 RNA-triggered gene silencing. Trends in Genetics 15 385-363.

Fire A, Xu S, Montgomery MK, Kostas SA, Driver S \& Mello CG 1998 Potent and specific interference double-stranded RNA in Caenorhabditis elegans. Nature 391 806-811.

Fisher DL, Brassac T, Galas S \& Doree M 1999 Dissociation of MAP kinase activation and MPF activation in hormones stimulated maturation of Xenopus oocytes. Development 126 4537-4546.

Frank-Vaillant M, Jessus C, Ozon R, Maller JL \& Haccard O 1999 Two distinct mechanisms control the accumulation of cyclin B1 and Mos in Xenopus oocytes in response to progesterone. Molecular Biology of the Cell 10 3279-3288.

Freeman RS, Pickham KM, Kanki JP, Lee BA, Pena SV \& Donoghue DJ 1989 Xenopus homolog of the mos protooncogene transforms mammalian fibroblasts and induces maturation of Xenopus oocytes. PNAS 86 5805-5809.

Gavin AC, Cavadore JC \& Schorderet-Slatkin S 1994 Histone H1 kinase activity, germinal vesicle breakdown and $\mathrm{M}$ phase entry in mouse oocytes. Fournal of Cell Science 107 275-283.

Goren S \& Dekel N 1994 Maintenance of meiotic arrest by a phosphorylated p34 cdc2 is independent of cyclic adenosine 3',5'-monophosphate. Biology of Reproduction 51 956-962.

Gotoh Y, Moriyama K, Matsuda S, Okumura E, Kishimoto T, Kawasaki H, Suzuki K, Yahara I, Sakai H \& Nishida E 1991 a Xenopus M phase MAP kinase: isolation of its cDNA and activation by MPF. EMBO fournal 10 2661-2668.

Gotoh Y, Nishida E, Matsuda S, Shiina N, Kosako H, Shiokawa K, Akiyama T, Ohta K \& Sakai H $1991 b$ In vitro effects on microtubule dynamics of purified Xenopus M phase-activated MAP kinase. Nature 349 251-254.

Gotoh Y, Masuyama N, Dell K, Shirakabe K \& Nishida E 1995 The MAPK cascade: its role in Xenopus oocytes, eggs and embryos. Progress in Cell Cycle Research 1 287-297.

Gross SD, Schwab MS, Taieb FE, Lewellyn AL, Qian YW \& Maller JL 2000 The critical role of the MAP kinase pathway in meiosis II in Xenopus oocytes is mediated by p90(RSK). Current Biology 10 430-438.

Gross SD, Lewellyn AL \& Maller JL 2001 A constitutively active form of the protein kinase p90 RSK 1 is sufficient to trigger the G2/M transition in Xenopus oocytes. Fournal of Biological Chemistry 49 46099-46103.
Haccard O, Lewellyn A, Hartley RS, Erikson E \& Maller JL 1995 Induction of Xenopus oocyte meiotic maturation by MAP kinase. Developmental Biology 168 677-682.

Hammond SM, Bernstein E, Beach D \& Hannon GJ 2000 An RNA-directed nuclease mediates post-transcriptional gene silencing in Drosophila cells. Nature 404 293-296.

Hashimoto N 1996 Role of c-mos proto-oncogene product in regulation of mouse oocyte maturation. Hormone Research $\mathbf{4 6}$ $11-14$.

Hashimoto N, Wanatabe N, Furuta Y, Tatemoto H, Sagata N, Yokoyama M, Okazaki K, Nagayoshi M, Takeda N \& Ikawa Y 1994 Parthenogenetic activation of oocytes in c-mos-deficient mice. Nature $37068-71$.

Hochegger H, Klotzbucher A, Kirk J, Howell M, le Guellec K, Fletcher K, Josefsberg BL, Galiani D, Lazar S, Kaufman O, Seger R \& Dekel N 2003 MPF governs MAPK activation and interphase suppression during meiosis of rat oocytes. Biology of Reproduction 68 1282-1290.

Hochegger H, Klotzbucher A, Kirk J, Howell M, le Guellec K, Fletcher K, Duncan T, Sohail M \& Hunt T 2001 New B-type cyclin synthesis is required between meiosis I and II during Xenopus oocyte maturation. Development 128 3795-3807.

Huang W, Kessler DS \& Erikson RL 1995 Biochemical and biological analysis of Mek1 phosphorylation site mutants. Molecular Biology of the Cell $\mathbf{4 0 4} 293-296$.

Josefberg LB, Galiani D, Lazar S, Kaufman O, Seger R \& Dekel N 2003 Maturation-promoting factor governs mitogen-activated protein kinase activation and interphase suppression during meiosis of rat oocytes. Biology of Reproduction 68 1282-1290.

Kenerdell JR \& Carthew RW 1998 Use of dsRNA-mediated genetic interference to demonstrate that frizzled and frizzled 2 act in the wingless pathway. Cell 95 1017-1026.

Kosako H, Gotoh Y \& Nishida E 1994 Requirement for the MAP kinase kinase/MAP kinase cascade in Xenopus oocyte maturation. EMBO fournal 13 2131-2138.

Laemmli UK 1970 Cleavage of structural protein during the assembly of the head of T4 bacteriophage. Nature 227 680-685.

Lazar S, Galiani D \& Dekel N 2002 cAMP-dependent PKA negatively regulates polyadenylation of $\mathrm{c}-\mathrm{mos} \mathrm{mRNA}$ in rat oocytes. Molecular Endocrinology 16 331-341.

Lee SB \& Esteban M 1994 The interferon-induced double-stranded RNA-activated protein kinase induces apoptosis. Virology 199 491-496.

Li YX, Farrell MJ, Liu R, Mohanty N \& Kirby ML 2000 Double-stranded RNA injection produces null phenotypes in zebrafish. Developmental Biology $217394-405$.

Maller J \& Krebs E 1977 Progesteron-stimulated meiotic cell division in Xenopus oocytes. Fournal of Biological Chemistry 525 1712-1718.

Marcus PI 1983 Interferon induction by viruses: one molecule of dsRNA as the threshold for interferon induction. Interferon $\mathbf{5}$ 115-180.

Meijer L \& Kim SH 1997 Chemical inhibitors of cyclin-dependent kinases. Methods in Enzymology $283204-209$.

Meijer L, Borgne A, Mulner O, Chong JP, Blow JJ, Inagaki N, Inagaki M, Delcros JG \& Moulinoux JP 1997 Biochemical and cellular effects of roscovitine, a potent and selective inhibitor of the cyclin-dependent kinases cdc2, cdk2 and cdk5. European fournal of Biochemistry 243 527-536.

Montgomery MK, Xu S \& Fire A 1998 RNA as a target of double-stranded RNA-mediated genetic interference in Caenorhabditis elegans. PNAS 95 15502-15507.

Nebrada AR \& Hunt T 1993 The c-mos proto-oncogene protein kinase turns on and maintains the activity of MAP kinase, but not MPF, in cell-free extracts of Xenopus oocytes and eggs. EMBO Fournal 12 1979-1986.

Nebreda AR, Gannon JV \& Hunt T 1995 Newly synthesized protein(s) must associate with $\mathrm{p} 34 \mathrm{cdc} 2$ to activate MAP kinase 
and MPF during progesterone-induced maturation of Xenopus oocytes. EMBO Fournal 14 5597-5607.

O'Keefe SJ, Kiessling AA \& Cooper GM 1991 The c-mos gene product is required for cyclin $\mathrm{B}$ accumulation during meiosis of mouse eggs. PNAS $\mathbf{8 8}$ 7869-7872.

Pincus G \& Enzmann EV 1935 The comparative behaviour of mammalian egg in vivo and in vitro. Fournal of Experimental Medicine 62 655-675.

Sagata N 1997 What does Mos do in oocytes and somatic cells? Bio Essays 19 13-21.

Sagata N, Daar I, Oskarsson M, Showalter S \& Vande Woude GF 1989 The product of mos proto-oncogene serves as a candidate 'initiator' for oocyte maturation. Science 245 643-645.

Sheets MD, Wu M \& Wickens M 1995 Polyadenylation of c-mos mRNA as a control point in Xenopus meiotic maturation. Nature $374511-516$.

Svoboda P, Stein P, Hayashi H \& Schultz RM 2000 Selective reduction of dormant maternal mRNAs in mouse oocytes by RNA interference. Development 127 4147-4156.

Tsafriri A \& Dekel N 1994 Molecular mechanisms in ovulation. In Molecular Biology of the Female Reproductive System. ed JK Findly. pp 207-258. San Diego; Academic Press.

Tsafriri A, Lindner HR, Zor U \& Lamprecht A 1972 In-vitro induction of meiotic division in follicle-enclosed rat oocytes by $\mathrm{LH}$, cyclic AMP and prostaglandin $\mathrm{E}_{2}$. Fournal of Reproduction and Fertility 31 39-50.

Tuschl T, Zamore PD, Lehmann R, Bartel DP \& Sharp PA 1999 Targeted mRNA degradation by double-stranded RNA in-vitro. Genes and Development 13 3191-3197.

Verlhac MH, Kubiak JZ, Clarke HJ \& Maro B 1994 Microtubule and chromatin behaviour follow MAP kinase activity but not
MPF activity during meiosis in mouse oocytes. Development 120 $1017-1025$.

Verlhac MH, Kubiak JZ, Weber M, Geraud G, Colledge WH, Evans MJ \& Maro B 1996 Mos is required for MAP kinase activation and is involved in microtubule organization during meiotic maturation in the mouse. Development 122 815-822.

Wianny F \& Zernicka-Goetz M 2000 Specific interference with gene function by double-stranded RNA in early mouse development. Nature Cell Biology 2 70-75.

Winston NJ 1997 Stability of cyclin B protein during meiotic maturation and the first meiotic cell division in mouse oocytes. Biology of the Cell 89 211-219.

Yew N, Mellini ML \& Vande Woude GF 1992 Meiotic initiation by the mos protein in Xenopus. Nature 355 649-652.

Yung Y, Dolginov Y, Yao Z, Rubinfeld H, Michael D, Hanoch T, Roubini E, Lando Z, Zharhari D \& Seger R 1997 Detection of ERK activation by a novel monoclonal antibody. FEBS Letters 408 292-296.

Zernicka-Goetz M, Verlhac MH, Geraud G \& Kubiak JZ 1997 Protein phosphatases control MAP kinase activation and microtubule organization during rat oocyte maturation. European Journal of Cell Biology 72 30-38.

Zhao X, Batten B, Singh B \& Arlinghaus RB 1990 Requirement of the c-mos protein kinase for murine meiotic maturation. Oncogene 5 1727-1730.

Received in final form 17 March 2004

Accepted 31 March 2004

Made available online as an Accepted Preprint 14 April 2004 